\title{
Contesting estimates of cryopreserved embryos in the United States
}

To the Editor:

In a 2013 Correspondence in Nature Biotechnology, Lomax and Trounson ${ }^{1}$ updated a 2003 estimate of the number of cryopreserved embryos in the United States. Whereas the earlier study ${ }^{2}$ arrived at a number of $\sim 400,000$, the new estimate was $\sim 1.39$ million. Empirical research on the number of cryopreserved embryos in the United States is lacking, and Lomax and Trounson ${ }^{1}$ discuss the assumptions that went into their calculation as well as several factors they could not quantify that would alter the total. On balance, they say, 1.39 million is a "conservative" estimate, with the true number likely to be higher. We identified several flaws in their data that underscore the inaccuracy of the new estimate.

Their total of 1.39 million embryos is the sum of (i) the $\sim 400,000$ embryos in the 2003 study ${ }^{2}$ and (ii) the number of embryos they estimate were stored in 2005-2010 (they say that data from 2004, 2011 and 2012 were not available). The latter is calculated from the number of live-birth deliveries in those years due to assisted reproductive technology (ART), which is well documented. For every one such delivery, Lomax and Trounson ${ }^{1}$ assume that five excess embryos were stored. However, their data have several errors. The number of live-birth deliveries in 2006 $(30,787)$ does not match CDC data ${ }^{3}$ and appears to be a duplication error (the same number appears for 2009). The data for 2005 (ref. 4) and 2010 (ref. 5) are for fresh and frozen nondonor and donor cycles, whereas the data for 2007 (ref. 6), 2008 (ref. 7) and 2009 (ref. 8) are for fresh nondonor cycles only. Lomax and Trounson ${ }^{1}$ should have included only live-birth deliveries with fresh-and not frozen - nondonor and donor cycles. Frozen cycles do not generate excess stored embryos; rather, they deplete them. They should also have included donor cycles for 2007-2009. Finally, it is unclear why the CDC data for 2004 (ref. 9) were not included. These data are corrected in Supplementary Table 1.

Lomax and Trounson ${ }^{1}$ note that 1.39 million embryos is likely an underestimate for several reasons. An important one is that "the majority of women undergoing ART procedures do not become pregnant and may discontinue treatment, leaving additional cryopreserved embryos in storage"1.
Therefore, it would be more accurate to use not the number of live-birth deliveries but the number of fresh nondonor and donor embryo transfers, which for 2004-2012 was 823,284 (Supplementary Table 2). If we assume five stored embryos for each transferred embryo, the total would be 4,116,420-about threefold higher than 1.39 million. To be clear, we are not proposing this number as a correction to 1.39 million given the methodological difficulties of generating this estimate.

Lomax and Trounson ${ }^{1}$ acknowledge some but not all of these difficulties. Their assumption of five stored embryos per live delivery is based solely on data from eight northern California clinics (whose actual rate was seven embryos per live delivery $)^{10}$, which may not hold nationally. And although they note that "improvements in ART pregnancy success rates may have resulted in a higher proportion of unused embryos," 1 they do not mention other changes in ART practice since 2003 that may be relevant. For example, the move to embryo transfer at the blastocyst stage may have decreased the proportion of stored embryos to live-birth deliveries ${ }^{11}$, whereas wider use of single-embryo transfer and improved freezing technology may have increased it.

These issues highlight the need for empirical research on the number of cryopreserved embryos in the United States and elsewhere to provide a sound basis on which to develop guidelines, policies and laws governing both ART treatment and embryo research.

\section{COMPETING FINANCIAL INTERESTS}

The authors declare no competing financial interests.

Dave Snow ${ }^{1}$, Alana Cattapan ${ }^{2}$ \&

Françoise Baylis ${ }^{2,3}$

${ }^{1}$ Department of Political Science, University of Guelph, Guelph, Ontario, Canada. ${ }^{2}$ Faculty of Medicine, Dalhousie University, Halifax, Nova Scotia, Canada. ${ }^{3}$ Faculty of Arts and Social Sciences, Dalhousie University, Halifax, Nova Scotia, Canada.

e-mail:snow@uoguelph.ca

1. Lomax, G.P. \& Trounson, A.O. Nat. Biotechnol. 31, 288-290 (2013)

2. Hoffman, D.I. et al. Fertil. Steril. 79, 1063-1069 (2003).

3. Centers for Disease Control and Prevention. http://www. cdc. gov/art/Archived-PDF-Reports/2006ART.pdf (2008).

4. Centers for Disease Control and Prevention. http://www.
cdc.gov/art/Archived-PDF-Reports/2005ART508.pdf (2007).

5. Centers for Disease Control and Prevention. http:/ www.cdc.gov/art/ART2010/PDFs/ART_2010_National_ Summary_Report.pdf (2012).

6. Centers for Disease Control and Prevention. http://www. cdc.gov/art/Archived-PDF-Reports/COMPLETE_2007_ ART.pdf (2009).

7. Centers for Disease Control and Prevention. http://www. cdc.gov/art/Archived-PDF-Reports/ART_2008_Full.pdf (2010).

8. Centers for Disease Control and Prevention. http://www. cdc.gov/art/Archived-PDF-Reports/ART_2009_Full.pdf (2011).

9. Centers for Disease Control and Prevention. http://ftp. cdc.gov/pub/publications/art/2004ART508.pdf (2006).

10. Nachtigall, R.D. et al. Fertil. Steril. 92, 2094-2096 (2009).

11. Beesley, R., Robinson, R., Propst, A., Arthur, N. \& Retzloff, M. Fertil. Steril. 91, 1717-1720 (2009).

\section{Lomax and Trounson reply:}

Our 2013 Correspondence ${ }^{1}$ focuses on the "imbalance between the potential supply of embryos and the ability to use them in research.” It is motivated by our frequent interaction with prospective embryo donors who aspire to contribute to stem cell research. We emphasize specific remedies to enhance the efficacy of the informed consent process.

We illustrate the imbalance with an updated estimate of the number of embryos stored in the United States. Both we and Snow, Cattapan and Baylis ${ }^{2}$ acknowledge that assumptions underpinning our method are inherently conservative, such that our estimate of "more than 1 million" is likely low. By way of comparison, at the end of $2011,839,325$ embryos were in storage in the $\mathrm{UK}^{3}$, where the Human Fertilisation and Embryology Authority collects data on human embryos.

Snow, Cattapan and Baylis provide cogent corrections and methodological insights to improve data consistency. However, precisely quantifying the number of stored embryos is secondary to our main argument concerning the ethics and policy imperative-that we must explicitly inform donors about the limited ability to use surplus embryos in stem cell research.

1. Lomax, G.P. \& Trounson, A.O. Nat. Biotechnol. $\mathbf{3 1}$ 288-290 (2013).

2. Snow, D., Cattapan, A. \& Baylis, F. Nat. Biotechnol. 33 909 (2015).

3. UK Parliament Daily Hansard. Embryology, column WA26. http://www.publications.parliament.uk/pa/ Id201213/ldhansrd/text/130108w0001.htm (8 Jan 2013; accessed 7 July 2015). 